\section{Duelling letters: which one would you sign?}

\author{
Coral Gartner, ${ }^{1}$ Ruth E Malone ${ }^{2}$
}

Big Tobacco has got to be pretty pleased at the media storm over duelling letters sent by public health scientists and practitioners to the Director-General of the WHO concerning tobacco harm reduction and e-cigarettes. The first of these letters, with 53 signatories, argued in favour of including harm reduction strategies in WHO's approach to tobacco control and proposed a set of 10 guiding principles for formulating policy around nicotine products. ${ }^{1}$ In response, a second letter was sent with 129 signatories, which emphasised the involvement of tobacco companies in the e-cigarette market and argued against exempting e-cigarettes from any provisions of the WHO Framework Convention on Tobacco Control (FCTC). ${ }^{2}$

As signers of the first and second letters, respectively, who found ourselves pressed to choose among positions with which each of us did not entirely agree, we are dismayed at the eagerness with which some on both sides have fanned the flames of division-and baffled at how the e-cigarette issue has consumed attention that should be directed to the real killer products: conventional cigarettes, the manufacturers of which continue business as usual (while buying up controlling interests in popular e-cigarette companies).

Harm reduction has long been a source of conflict in the tobacco control field, following the lasting damage from the tobacco industry's cynical 'lights' and 'low tar' cigarette scams. ${ }^{3}$ Unlike strategies that focus solely on reducing smoking uptake and increasing quitting, encouraging smokers to switch to less harmful nicotine products (such as snus or e-cigarettes) could detract from existing strategies if smokers engaged in dual use of such products and conventional cigarettes rather than quitting; or if young non-smokers use e-cigarettes and then progress to combustible cigarettes via 'gateway' effects.

\footnotetext{
${ }^{1}$ UQ Centre for Clinical Research, The University of Queensland, Herston, Queensland, Australia;

${ }^{2}$ Department of Social and Behavioral Sciences, School of Nursing, University of California, San Francisco, San Francisco, California, USA

Correspondence to Dr Coral Gartner, UQ Centre for Clinical Research, The University of Queensland, Building 71/918, Royal Brisbane and Women's Hospital Site, Herston, QLD 4029, Australia; c.gartner@uq.edu.au
}

Whether these potential adverse consequences would exceed the potential benefits (such as encouraging more smokers to stop smoking), is uncertain and likely to be influenced by how all nicotine products (including cigarettes) are regulated.

The duelling WHO letters have resulted in a public division among tobacco control advocates, between those who 'support' harm reduction approaches and those who 'do not'. Creating and exploiting this type of division over harm reduction was long ago identified as a goal of the major tobacco company Philip Morris. ${ }^{4}$ But the apparent division between signatories on these letters likely represents a false dichotomy that obscures what could potentially be substantial areas of agreement. These include the need for e-cigarette regulation to improve quality control (including packaging and labelling), restricting advertising and prohibiting sales to minors. Including e-cigarettes under clean air policies also has widespread support, although some feel the precautionary principle should be set aside in favour of allowing behaviour that is likely less harmful than smoking. (In practice, communities with clean air laws are quickly ensuring that new sources of pollutants, even if safer than cigarettes, are not introduced. ${ }^{5}$ )

Radical libertarians who disfavour government regulation of anything will argue that conventional cigarettes will die a natural death if the 'disruptive technology' of e-cigarettes is left to flourish. They see e-cigarettes as offering a universal solution that will end the tobacco epidemic. Such unbridled enthusiasm ignores the extensive history of tobacco industry innovation and deception.

Those who aggressively oppose e-cigarettes see them as a serious threat that could reverse the downward smoking prevalence trend in many countries, and fear that their sanction would renormalise tobacco use behaviours, undermine existing tobacco control measures and offer Big Tobacco new opportunities for hooking kids on nicotine.

However, there are also many like us on both sides, who occupy the middle ground. We see the likely effect of products like e-cigarettes as "somewhere in between, with both pros and cons to recommend or discourage their use." ${ }^{7}$ For those in this larger middle group who do believe that the government has a reasonable role in protecting the public from dangerous products, it is clear that combustible cigarettes should no longer be widely and easily available. The historical record shows that the commercial manufacture, promotion and sale of cigarettes created an unprecedented industrially produced disease epidemic. ${ }^{8}$ That is our biggest and most intractable problem, almost everyone agrees. What level of regulation is most appropriate for a product that is likely to be far less deadly than combustible cigarettes, yet is still addictive and may still entail some risk to users is less clear.

The rise of the e-cigarette market should not have taken anyone in public health by surprise as the development of inhaled novel nicotine products was anticipated by many tobacco control experts long before anyone coined the term 'e-cigarette'. 7910 Similarly, many of the issues concerning the potential harms and benefits of e-cigarettes that are now being fiercely debated have been previously identified and discussed extensively at numerous conferences, symposiums and advisory committees stretching back nearly 20 years. ${ }^{11-19}$ Yet despite around two decades of serious discussions, no country has managed to anticipate and develop a regulatory framework to address the concerns associated with e-cigarettes ahead of their arrival and mass uptake. Even in countries where legal barriers preclude their sale and use, such as Australia, internet shopping has resulted in a substantial black market of unregulated nicotine products. ${ }^{20}$

For good or ill, numerous nicotine products, including e-cigarettes, are now part of the tobacco control landscape. Rather than continuing policy debates about whether e-cigarettes should be 'supported' or 'opposed', it is time to maximise the opportunity these products may provide to leverage greater regulation of smoked tobacco. This should be done by explicitly linking e-cigarette regulation to the simultaneous 'endgame' dialogues occurring in many countries. ${ }^{21-26}$ Every time e-cigarettes are discussed, we should make explicit links with conventional combusted cigarettes, linking any proposals for less stringent regulations of the former to proposals for more stringent regulation (or even phaseout of sales) of the latter. We should name the goal, which is ending the smoked tobacco epidemic, and consider how ecigarettes (and other alternative nicotine products) could figure as part of a comprehensive strategy with the ultimate goal of eradicating use of combustible cigarettes. 
While there are potential downsides to such an approach, the prospect of bringing the modern cigarette epidemic to a close in our lifetimes would be worth the risks. It is inconceivable that non-combusted nicotine products could cause premature deaths in the great numbers we know conventional cigarettes have caused. Perhaps the greatest contribution these alternative products may ultimately make is in providing further justification for phasing out the most harmful nicotine product: the cigarette. Similarly, their greatest risk to public health may be in diverting attention from making that goal a reality.

Competing interests $\mathrm{CG}$ is funded by a grant from the National Health and Medical Research Council (NHMRC) (GNT1061978), has received support from VicHealth to conduct an economic analysis of tobacco harm reduction, and is the chief investigator of a clinical trial of electronic nicotine delivery systems for smoking cessation funded by a NHMRC project grant (GNT1020123). REM is funded by the National Institutes of Health (NCI and NIDA). She owns one share each of Reynolds American, Altria and Philip Morris International stock for research and advocacy purposes.

Provenance and peer review Not commissioned; internally peer reviewed.

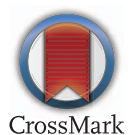

To cite Gartner C, Malone RE. Tob Control 2014:23:369-370.

Tob Control 2014;23:369-370.

doi:10.1136/tobaccocontrol-2014-051933

\section{REFERENCES}

1 Abrams D, Axéll T, Bartsch $P$, et al. Statement from specialists in nicotine science and public health: reducing the toll of death and disease from tobacco -tobacco harm reduction and the Framework Convention on Tobacco Control (FCTC) [Correspondence 26 May 2014]. http://nicotinepolicy. net/documents/letters/MargaretChan.pdf (accessed 23 Jul 2014)

2 Aktan Ö, Alexanderson K, Allebeck P, et al. 129 public health and medical authorities from 31 countries write WHO DG Chan urging evidence-based approach to ecigs [Correspondence 16 Jun 2014] https://tobacco.ucsf.edu/sites/tobacco.ucsf.edu/files/ u9/Chan-letter-June16\%20PST\%20FINAL\%20with\% 20129\%20sigs.pdf (accessed 23 Jul 2014).

3 Hall W, Gartner C. Supping with the Devil? The role of law in promoting tobacco harm reduction using low nitrosamine smokeless tobacco products. Public Health 2009:123:287-91.

4 McDaniel PA, Smith EA, Malone RE. Philip Morris's Project Sunrise: weakening tobacco control by working with it. Tob Control 2006;15:215-23.

5 Whitcomb D, Gorman S. Los Angeles moves to ban e-cigarettes, joining NY, others. Tue Mar 4, 2014 8:56pm EST. Los Angeles: Reuters, 2014.

6 Glynn TJ. E-cigarettes and the future of tobacco control. CA Cancer J Clin 2014;64:164-8.

7 Warner K. Tobacco harm reduction: promise and perils. Nicotine Tob Res 2002;4:S61-71.

8 Proctor RN. Golden Holocaust: origins of the cigarette catastrophe and the case for abolition. Berkeley, CA: University of California Press, 2012

9 Foulds J. Nicotine replacement therapy does work: time to stop sitting on the fence. A reply. Addiction 1994;89:438-9.

10 Shiffman S, Gitchell JG, Warner KE, et al. Tobacco harm reduction: conceptual structure and nomenclature for analysis and research. Nicotine Tob Res 2002;4:5113-29.

11 Royal College of Physicians. Ending tobacco smoking in Britain: radical strategies for prevention and harm reduction in nicotine addiction. A report by the
Tobacco Advisory Group of the Royal College of Physicians. London: RCP, 2008.

12 Hébert $R$ (ed). What's new in Nicotine \& Tobacco Research? Nicotine Tob Res 2002;4:S47-52.

13 Stratton K, Shetty P, Wallace R, et al.; eds. Clearing the smoke: assessing the science base for tobacco harm reduction. Washington DC: National Academy Press, 2001.

14 Smoking cessation: alternative strategies. Tob Control 1995:4:S1-90.

15 Conference on tobacco dependence: innovative regulatory approaches to reduce death and disease: selected excerpts from conference proceedings. Food Drug Law J 1998;53:115-37.

16 Reducing Tobacco Harm Conference; 2001 May 1011; Arlington, Virginia.

17 Alternative Nicotine Delivery Systems: Harm Reduction and Public Health Conference. Toronto, 1997.

18 Public Health England. Electronic cigarettes and tobacco harm reduction symposium. 15 May 2014. London, UK. https://publichealthmatters.blog.gov.uk/ resources-from-the-electronic-cigarettes-and-tobaccoharm-reduction-symposium/

19 Ferrance R, ed. Nicotine and public health. American Public Health Association, 2000.

20 Hall W, Gartner C. Should Australia reconsider its ban on the sale of electronic nicotine delivery systems? Lancet Resp Med 2014;2:602-4

21 Gartner C, Hall W, Borland R. How should we regulate smokeless tobacco products and e-cigarettes? Med J Aust 2012;197:611-12.

22 Malone RE. Tobacco endgames: what they are and are not, issues for tobacco control strategic planning, and a possible US scenario. Tob Control 2013:22:i42-4.

23 Malone RE, McDaniel PA, Smith EA. Tobacco control endgames: global initiatives and implications for the UK. Cancer Research UK, 2014.

24 Malone RE, McDaniel PA, Smith EA. It is time to plan the tobacco endgame. BMJ 2014;348:g1453.

25 Smith EA. Questions for a tobacco-free future. Tob Control 2013:22:11-2.

26 Warner KE. An endgame for tobacco? Tob Control 2013;22:i3-5. 